\title{
Review
}

\section{Review on Dissociative Anaesthetics and Compatible Drug Combinations in Veterinary Clinical Practice}

\author{
Jiregna Dugassa, DVM*; Abebe Fromsa, DVM, MVSc ${ }^{2}$ \\ 'School of Veterinary Medicine, College of Medical and Health Sciences, Wollega University, Nekemte, Ethiopia \\ ${ }^{2}$ Department of Clinical Studies, College of Veterinary Medicine and Agriculture, Addis Ababa University, Bishoftu, Ethiopia
}

\section{"Corresponding author}

Jiregna Dugassa, DVM

School of Veterinary Medicine, College of Medical and Health Sciences, Wollega University, P.O.Box, 395, Nekemte, Ethiopia;Tel. +25192। I80037;

E-mail: ¡iregnadu@gmail.com

\section{Article information}

Received: June 20 ${ }^{\text {th }}, 2018$; Revised: November $4^{\text {th }}, 2018$; Accepted: November 6 $6^{\text {th }}, 2018$; Published: November $9^{\text {th }}, 2018$

\section{Cite this article}

Dugassa J, Fromsa A. Review on dissociative anaesthetics and compatible drug combinations in veterinary clinical practice. Vet Med Open J.20I8; 3(I): 2I-30. doi: $10.17140 /$ VMOJ-3-129

\section{| ABSTRACT |}

\section{Background}

Dissociative anesthesia is a form of anesthesia characterized by catalepsy, catatonia, analgesia, and amnesia. Although some reviews and research findings are conducted regarding dissociative anaesthetics and its combination with other compatible drugs as clinical use, the information is highly scattered, not well compiled and presented for commercialization specially in Veterinary Medicine.

\section{Aim}

To review on importance of dissociative anaesthetics and its clinical relevance, and to review on combination of dissociative anaesthetics with other compatible drugs and its application in veterinary practices.

\section{Conclusion}

Dissociative anesthetic combinations are effective anesthetic induction regimens and can be used both to induce and maintain anesthesia in surgical procedures of mild to moderate intensity and short duration. Dissociative anesthesia resembles a cataleptic state in which the patient appears to be asleep, but does not respond to external stimuli. Ketamine and tiletemine is the common drug of this group mainly used in animals effectively. These drugs are mainly characterized by analgesia and superficial sleep with good somatic analgesia but poor visceral analgesia and muscle relaxation.

\section{Keywords}

Clinical use; Ketamine; Tiletemine.

\section{INTRODUCTION |}

$\mathrm{D}$ issociative anesthesia is a form of anesthesia characterized by catalepsy, catatonia, analgesia, and amnesia. It does not necessarily involve loss of consciousness and thus does not always imply a state of general anesthesia. Dissociative anesthetics probably produce this state by interfering with the transmission of incoming sensory signals to the cerebral cortex and by interfering with communication between different parts of the Central Nervous System (CNS).

The common dissociative anaesthetics of veterinary importace: includes ketamine and tiletamine (in Telazol ${ }^{\circledR}$ ). Their combinations are effective anesthetic induction regimens and can be used both to induce and maintain anesthesia in procedures of mild to moderate surgical intensity and short duration. For instance, ketamine and xylazine produce lateral recumbence and anesthesia adequate for endotracheal intubation, gastrointestinal endoscopy, and most minor procedures. A combination of ketamine and medetomidine or dexmedetomidine produces immobilization, analgesia, and excellent muscle relaxation for $60 \mathrm{~min}^{2}$

Several drugs are used intravenously, singly or in combination with other drugs to achieve an anaesthetic state as components of balanced anaesthesia. These drugs include the following; barbiturates (thiopental, methohexital), benzodiazepines (midazolam, diazepam), opioids (morphine, fentanyl, alfentanil, remifentanil), propofol, ketamine and miscellaneous drugs (droperidol, 
etomidate, medetomidine). ${ }^{3}$ The drug is an arylcyclohexylamine chemically related to phencyclidine, ketamine is the only intravenous anaesthetic that possesses analgesic properties and produces cardiovascular stimulation. ${ }^{4} \mathrm{~A}$ part from the required actions of sedation, hypnosis and analgesia, medetomidine has the usual marked cardiovascular effects of bradycardia and decrease cardiac output. ${ }^{5}$

Indeed, medetomidine/ketamine combinations have been found to provide excellent immobilization and relaxation in a wide range of species of animals ${ }^{6}$ investigated the suitability of detomidine-midazolam-ketamine combination for umbilical surgery in calves. The study reported satisfactory immobilization for umbilical surgery, although some hypoxaemia and respiratory acidosis occurred, body temperature of the calves decreased significantly with good relaxation and no complications. Similarly, in a report by Afshar FS et $\mathrm{al}^{7}$ on the effect of xylazine-ketamine on arterial blood pressure, heart and respiratory rates in goats, it was found that heart rate decreased at 15 to $60 \mathrm{~min}$., but without significant change in respiratory rate.

\section{DISSOCIATIVE ANAESTHETICS AND COMPATIBLE DRUG COMBINATIONS IN VETERINARY CLINICAL PRACTICE |}

\section{Dissociative Anaesthetics}

Dissociatives are a class of hallucinogens which distort perceptions of sight, sound and produce feelings of detachment-dissociation-from the environment and self. This is done through reducing or blocking signals to the conscious mind from other parts of the brain. Dissociative agents may be administered via many routes. Phencyclidine is often consumed orally, as thermal degradation results in inactivation of nearly $50 \%$ of the drug when smoked. ketamine can be consumed either orally or parenterally, although poor oral bioavailability makes insufflations the preferred method. ${ }^{8}$

Ketamine is congener of phencyclidine. It was first used in human anesthesia in 1965 and in veterinary anesthesia, feline practice, in 1970. Although many kinds of drugs are capable of such action, the dissociatives are unique in that they do so in such a way that they produce hallucinogenic effects, which may include sensory deprivation, dissociation, hallucinations and dream like states or trances. Many dissociative have general depressant effects on respiration, produce sedation, analgesia and ataxia, as well as cognitive and memory impairment and amnesia. ${ }^{9}$

Generally, dissociative anesthesia implies dissociation from the surroundings with only superficial sleep mediated by interruption of neuronal transmission from the unconscious to conscious parts of the brain. During dissociative anesthesia, the animal maintains its pharyngeal, laryngeal, corneal, palpabral, and swallowing reflexes. The eyes also remain open. They increase muscle tone, spontaneous involuntary muscle movement (occasionally seizures are seen in some species). There is also increased salivation, lacrimation and good somatic analgesia. ${ }^{10}$

\section{Historical Background}

Dissociative anaesthetic agents have been used medicinally for decades, with phencyclidine (PCP) first having been used as an anesthetic in the 1950s. Early reports noted a profound state of anesthesia, in which major surgeries were performed without loss of respiratory drive; however, severe emergence reactions (including psychosis and hallucinations) limited PCP's use. ${ }^{3}$

Dissociative agents are abused recreationally. PCP ("angel dust") abuse reached epidemic proportions in the 1970s but its use today is sporadic. ketamine often referred to as "special K," "vitamin K," or "super K," has become popular at rave parties and night clubs in human. ${ }^{11}$

A few years later, in 1970, the federal government approved ketamine for human use, and as a result it soon became popular as a battlefield anesthetic. ${ }^{12}$ The first evidence of illicit abuse of the drug was on the West Coast. Later, during the late 1970 s and early 1980s abuse began to increase across the country, especially among certain sub-cultures (e.g., mind explorers and new age spiritualists). Around the same time, new forms of the drug were being introduced into the illegal drug markets including capsules, powder, crystals, tablets, and solutions, in addition to other injectable forms. Starting in the mid-1980s another increase in the social-recreational use of ketamine was beginning to be linked to various dance cultures, initially as an adulterant an added ingredient that can alter the effects of the drug. ${ }^{13}$

Due to the continued abuse of ketamine, in 1999 ketamine becomes a controlled substance in America.

1999: Time out magazine states that "ketamine is the new E" though it was dismissed years earlier as just a fad. ${ }^{6}$

2000: Ketamine is regulated under Schedule 1 of Hong Kong Chapter 134 of Dangerous Drugs Ordinance. It can only be used legally by health professionals, for university research purposes, or with a physician's prescription. ${ }^{1}$

2003-2005: MixMag dance magazine reports show steady increase in ketamine use year after year. Also DrugScope identifies it in its survey as growing UK phenomena. ${ }^{14}$

2005: UK anecdotal information on bladder problems due to ketamine use. Later dismissed by health professionals as ketamine is extremely safe in medical circles.

2006: Ketamine Class C drug in UK. Recreational use increases.

2007: In Hong Kong the first clinical reports of serious bladder and kidney problems among daily ketamine street use are published.

2008: Isolated reports of serious bladder problems with users across the UK. Reasons for this are still unknown as ketamine is considered a safe drug in medical circles and has received thousands of clinical trials which demonstrate its efficacy and safety. 2009: Druglink magazine highlights that ketamine use is still increasing in the UK despite it being a Class C drug. Some services are starting to also see an increase in injecting users as well as those snorting the drug. 
2010: Estimated 90,000 ketamine users in the UK.

2011: Report released in the UK by Lancaster University stating that ketamine can cause cystitis in human tissue.

2014: Use of ketamine has decreased from its peak in many parts of the UK though there have been anecdotal reports that it is being mixed with mephedrone. ${ }^{14}$

More recently, ketamine has been introduced for sedation and general anesthesia, as well as an adjunct to treat refractory unipolar major depressive disorder, posttraumatic stress disorder, and acute suicidal ideation. ${ }^{15}$ Despite difficulty in determining its prevalence, use is higher today than it was when first introduced.

\section{General Characteristics}

Dissociative anaesthetics are mainly characterized by good analgesia of superficial somatic parts, poor visceral analgesia and muscle relaxation. Catalepsy is noticed with rigidity and partial extension of limbs. The drug rapidly crosses the placental barrier and affect foetus. ${ }^{16}$

Dissociative anaesthetics are contra-indicated in animals with head trauma or space occupying lesion in the brain, corneal ulcers and lacerations. In human dreams and emergence of hallucinations are the features of its use and so administration is largely restricted to younger children. The other characteristics of dissociative anaesthetics are increasing muscle tone, spontaneous muscle movement (ocassionaly seizure), salivation, lacrimation, and dose dependent cardiovascular effects. ${ }^{15}$

\section{COMMON DISSOCIATIVE ANAESTHETICS}

Many drugs can lead to a dissociative state causing sensory deprivation, hallucinations or trances, and can also affect the body's dopamine and opioid system, leading to a feeling of euphoria. ${ }^{17}$ The most commonly used dissociative drugs are:

\section{Ketamine}

Ketamine, or ketamine hydrochloride, is a non-barbiturate, rapidacting dissociative anesthetic used on both animals and humans; it also has been used in human medicine for pediatric burn cases and dentistry, and in experimental psychotherapy. ${ }^{18}$ Ketamine is a liquid and the most potent ways of using it is by injecting intramuscularly or intravenously. There is the risk of losing motor control before injection is completed. ${ }^{19}$

\section{Chemical Structure}

Ketamine is 2-(o-chlorophenol)-2-(methylamino)-cyclohexanone hydrochloride. Two optical isomers of ketamine exist due to an asymmetric carbon. Most formulations contain the racemic mixture, but a purified S-ketamine formulation is available in some countries. The positive $(\mathrm{S})$ isomer produces more intense analgesia, is metabolized more rapidly, and has a lower incidence of emergence reactions than the negative $(\mathrm{R})$ isomer. Racemic ketamine is available as a $5 \%$ and $10 \%$ aqueous solution. It has a $\mathrm{pH}$ of $3.5-5.5$ and is preserved by benzethonium chloride. Ketamine is a water soluble phencyclidine derivative. ${ }^{20}$

\section{Tiletamine}

Tiletamine is also one of dissociative anesthetic and pharmacologically classified as an N-Methyl-D-Aspartate (NMDA) receptor antagonist. It is related chemically to ketamine. Tiletamine hydrochloride exists as odorless white crystals. It is used in veterinary medicine in the combination product "Telazol" or "Zoletil" (tiletamine/zolazepam, $50 \mathrm{mg} / \mathrm{ml}$ of each in $5 \mathrm{ml}$ vial) as an injectable anesthetic for use in cats and dogs. It is sometimes used in combination with xylazine (Rompun) to tranquilize large mammals such as polar bears and wood bison. Telazol is mostly the only commercially available tiletamine product in the world. It is contraindicated in patients (animals) with CNS signs, hyperthyroidism, cardiac disease, pancreatic or renal disease, pregnancy, glaucoma, or penetrating eye injuries. ${ }^{21}$

\section{Chemical Structure}

Tiletamine is 2-(ethylamino)-2-(2-thienyl)-cyclohexanone hydrochloride. Tiletamine/zolazepam combinations are available as a white powder that is reconstituted with $5 \mathrm{ml}$ of diluent. The final concentrations of tiletamine and zolazepam depend on the product being used. ${ }^{22}$

\section{MECHANISM OF ACTION OF DISSOCIATIVE ANAESTHETICS -}

The dissociative anesthetics act on NMDA, opioid, monoaminergic, and muscarinic receptors. Additionally, they interact with voltage gated calcium channels. Interestingly, the dissociative do not appear to interact with (Gamma-AminoButyric Acid)GABA receptors as the other injectable anesthetics do. Ketamine and tiletamine are non-competitive antagonists at the NMDA receptor. They bind to the phencyclidine-binding site, which prevents glutamate, an excitatory neurotransmitter, from binding. Prevention of glutamate binding results in depression of the thalamocortical, limbic, and reticular activating systems. ${ }^{22}$

Dissociatives have also been reported to have action at $\mu$, $\delta$, and $x$ opioid receptors. Activity at the opioid receptors imparts analgesic properties unlike other injectable anesthetics, although the clinical significance of this action at clinically relevant doses is debatable. ${ }^{11}$ 'Additionally, the dissociatives' interaction at monoaminergic receptors may also contribute to antinociception. Because dissociative anesthesia is associated with anticholinergic symptoms (emergence delirium, bronchodilation, and sympathomimetic actions), it is thought that these drugs have antagonist activity at muscarinic receptors. However, many of these effects may also be related to the sympathetic nervous system-stimulating effects of ketamine and tiletamine. ${ }^{23}$

It also interacts with opioid receptors, monoamine, cholinergic, purinergic and adrenoreceptor systems as well as having local anesthetic effects. ${ }^{24}$ Newly found mechanisms of action with 
newer clinical applications include:

I) NMDA receptor interaction with ketamine plays a role in the opioid induced antihyperalgesic effects of ketamine. ${ }^{22}$

II) Subanesthetic doses of ketamine via NMDA receptor blockade potentiate opioid analgesia. ${ }^{19}$

III) Ketamine also acts by suppressing the induction of no synthase activity and protein expression so that enhance the protection against sepsis process i.e. anti-inflammatory effect. ${ }^{25}$ IV) The hypnotic effects of ketamine are caused by a combination of immediate channel blockade of NMDA and hyperpolarization-activated cation channels. ${ }^{26}$

V) Its immediate analgesic effects are mediated predominantly by a combination of opioid system sensitization and antinociception. ${ }^{27}$

VI) Ketamine also inhibits tumor necrosis factor-alpha and interleukin-6 gene expressions in macrophages. ${ }^{28}$

\section{PHARMACOKINETICS OF DISSOCIATIVE ANAESTHETICS -}

\section{Central Nervous System}

The dissociative anaesthetics are similar to other injectable anesthetics in that they have a relatively rapid onset of action (especially when administered intravenously), have short duration, and are highly lipophilic. Unlike other injectable anesthetics, the dissociative are also effective when administered intramuscularly (IM). Peak plasma concentrations occur within 45-90 sec of IV administration and within $10 \mathrm{~min}$ following IM injection. The high lipid solubility of the dissociative ensures that the blood-brain barrier is crossed quickly, which establishes effective brain concentrations of the drugs. ${ }^{23}$

In most species, metabolism of the dissociatives occurs in the liver. Ketamine is demethylated by hepatic microsomal enzymes, producing the active metabolite norketamine. Eventually, norketamine is hydroxylated and then conjugated to form watersoluble and inactive glucuronide metabolites that are excreted by the kidney. ${ }^{11}$ This process differs in the cat, where ketamine is biotransformed to norketamine, which is excreted unchanged in the urine. Dissociatives should be used with care in animals with significant hepatic and/or renal dysfunction as prolonged anesthetic times may result. ${ }^{29}$

Tiletamine also undergoes hepatic metabolism and renal excretion. Since tiletamine is only supplied with zolazepam, the action of the benzodiazepine should also be discussed. In cats, the duration of action of zolazepam is longer than that of tiletamine. This means that the CNS effects of the benzodiazepine (sedation) are present longer than those of tiletamine. In the dog, the reverse is true; the duration of action of tiletamine is longer than zolazepam. This means that the effects of the dissociative are observed, including muscle rigidity, sympathetic stimulation, and emergence delirium. $^{19}$

Pigs appear to have a slow, calm recovery from tiletamine/ zolazepam combinations, while in horses an agitated recovery may be seen if additional sedation is not provided. If significant plasma levels of tiletamine are present, reversal of the benzodiazepine with flumazenil may result in an anxious recovery. ${ }^{20}$ Ketamine is highly lipid soluble and undergoes rapid breakdown and redistribution to peripheral tissues. It is metabolized extensively in the liver by $\mathrm{N}$-demethylation and ring hydroxylation pathways. Norketamine is the main metabolite and is one-third to one-fifth as potent as ketamine as an anesthetic. Ketamine is excreted in urine and faeces as norketamine and hydroxylated derivatives. It has a cumulative effect. Gradual resistance builds up on repeated administration. ${ }^{30}$

\section{Cardiovascular System}

Ketamine has a direct negative cardiac inotropic effect, but it is usually overcome by central sympathetic stimulation. Intravenous administration of ketamine increases systemic and pulmonary arterial pressure, heart rate, cardiac output, myocardial oxygen requirements, and cardiac work. It is likely that these changes are the result of direct stimulation of the CNS leading to increased sympathetic nervous system outflow. ${ }^{31}$ Ketamine also inhibits ${ }^{32}$ norepinephrine reuptake into postganglionic sympathetic nerve endings, leading to an increased concentration of plasma catecholamines. ${ }^{33}$

Critically ill patients may respond to induction of anesthesia with ketamine with a decrease in systemic blood pressure and cardiac output. The catecholamine stores and the sympathetic nervous system's compensatory mechanism may be exhausted, unveiling ketamine's negative inotropic effects. While healthy animals are usually tolerant of increased cardiac work, myocardial oxygen requirements, and heart rate, ketamine should be used with caution in those animals that have severe cardiovascular disease (e.g., uncontrolled hypertension, cardiomyopathy, or heart failure), and those that are already tachycardic and/or arrhythmic. Stimulation of the cardiovascular system in these patients may not be desirable. $^{21}$

\section{Respiratory System}

Unlike other injectable anesthetics, ketamine does not cause significant respiratory depression. Ventilatory responses to hypoxia and carbon dioxide are maintained in animals receiving ketamine as the sole anesthetic agent. ${ }^{34}$ When ketamine is administered with other CNS depressants, significant respiratory depression can occur. Ketamine administration has been associated with an 'apneustic' respiratory pattern, characterized by a prolonged inspiratory duration and relatively short expiratory time..$^{35}$

Despite this altered respiratory pattern, carbon dioxide levels and minute ventilation usually remain within normal limits. Ketamine is a bronchial smooth muscle relaxant and causes bronchodilation and a decrease in airway resistance which makes it an attractive choice when anesthetizing animals with asthma or obstructive airway diseases such as chronic obstructive pulmonary disease. ${ }^{36}$ 
Pharyngeal and laryngeal reflexes remain intact when ketamine is used as the sole anesthetic agent. It should be noted, however, that these reflexes are often uncoordinated and not protective. An endotracheal tube should always be placed to prevent aspiration. Maintaining a secure airway is especially important because ketamine increases salivation and respiratory tract secretions which can be reduced with the administration of an anticholinergic. $^{37}$

\section{Hepatic, Renal, Gastrointestinal Systems}

Laboratory tests that indicate hepatic or renal function are not altered by the administration of dissociatives. Gastrointestinal motility is unchanged after the administration of ketamine in the dog. ${ }^{38}$

\section{Muscle Tissue}

Unlike some other injectable anaesthetics, dissociatives may cause muscle rigidity and often spontaneous movement of the limbs, trunk, and/or head soon following injection. Substantial increases in intra ocular pressure (IOP) are seen after ketamine administration which may be a result of increased tone of the extraocular muscles. Muscle relaxation can be improved with the co-administration of benzodiazepines or $\alpha 2$-adrenergic receptor agonists. ${ }^{38}$

\section{Fetal/Neonatal Effects}

Ketamine crosses the placenta and enters fetal circulation. In a study conducted to evaluate the neurologic reflexes in puppies born via cesarean section, anesthetic induction of the dam with ketamine and midazolam which resulted in the most depression of neurologic reflexes when compared with other injectable induction drugs (chlorpromazine, thiopentone, midazolam and propofol). ${ }^{39}$

\section{SPECIES-SPECIFIC EFFECTS}

\section{Canine}

The dissociative anaesthetics can be administered either intravenously or intramuscularly to produce a range of effects from sedation to anesthesia. Induction of anesthesia with ketamine alone can lead to muscle rigidity, spontaneous movement, and undesirable recoveries. ${ }^{40}$ Therefore, it is usually administered with a coinduction agent such as a benzodiazepine. Because tiletamine is supplied as a combination with zolazepam, there is no need for additional benzodiazepine for intravenous administration. Intramuscular ketamine or tiletamine/zolazepam combinations are frequently combined with a $\alpha 2$-adrenergic receptor agonist and an opioid to produce excellent immobilization with muscle relaxation and analgesia. ${ }^{41}$

\section{Feline}

The dissociatives have been used to produce a range of effects from sedation to anesthesia in cats. These drugs can be administered intravenously or intramuscularly. Ketamine is also absorbed through the oral mucosa. In particularly fractious cats, ketamine can be sprayed into the mouth to effectively induce sedation and facilitate the induction of anesthesia. Copious salivation usually results due to the bitter taste and/or low $\mathrm{pH}$ of ketamine. $\alpha 2$ Adrenergic receptor agonists, benzodiazepines, and/or acepromazine are commonly administered in combination with intramuscular ketamine. The combination of dexmedetomidine, ketamine, and an opioid produces excellent chemical restraint/anesthesia, muscle relaxation, and. ${ }^{42}$

\section{Equine}

The dissociatives, particularly ketamine, are used extensively in equine anesthesia. Intravenous administration of the dissociatives rapidly and smoothly induces anesthesia provided that adequate sedation has been achieved prior to their administration. If the dissociatives are administered before adequate sedation has been provided, excitement will occur. Some muscle rigidity and involuntary movement may still occur when ketamine is used; therefore it is frequently combined with a co-induction agent such as a benzodiazepine, $\alpha 2$-adrenergic receptor agonist or. ${ }^{43}$

Anesthesia can be maintained by administering additional intravenous doses of ketamine. These doses may be administered as intermittent boluses or as a constant rate infusion. When used as a constant rate infusion, ketamine is frequently combined with sedatives and analgesic agents (e.g., $\alpha 2$-adrenergic receptor agonists, guaifenesin, and opioids) in a combination commonly referred to as 'triple drip'. 44

\section{Ruminant}

The dissociatives can be used in ruminants to induce anesthesia. Sedation and muscle relaxation are usually improved by the administration of an $\alpha 2$-adrenergic receptor agonist or benzodiazepine prior to the administration of ketamine. Anesthesia can be maintained with a constant rate infusion of ketamine or by a combination of ketamine, guaifenesin, and xylazine. Subanesthetic doses of ketamine (in combination with xylazine) have been administered to calves to produce sedation prior to castration. This so-called 'ketamine stun' technique may be an efficacious and cost-effective alternative or adjunct to local anesthesia for castration. ${ }^{44}$

\section{Swine}

The dissociatives have been used extensively in swine for chemical restraint and anesthesia. Ketamine does not induce malignant hyperthermia in susceptible pigs, although its use in these animals has been controversial. Similar to other species, ketamine as a sole anesthetic agent produces poor muscle relaxation so it is commonly combined with azaperone, benzodiazepines and/or $\alpha 2$-adrenergic receptor agonists for sedation and anesthesia. Tiletamine/zolazepam combinations are commonly reconstituted with $250 \mathrm{mg}$ of xylazine and $250 \mathrm{mg}$ of ketamine and used as an injectable anesthetic in swine. ${ }^{45}$ 


\section{Clinical Use}

Ketamine is very widely used for anaesthesia and analgesia by the veterinary profession. It is an essential anaesthetic for veterinary use because it is the only injectable anaesthetic that is safe and well tested in the full range of species that the veterinarian must treat. This includes both small and large domestic animals, neonates of pets and laboratory animals, large, wild and zoo animals. So it is safely used by virtually every veterinary practice throughout Europe and the rest of the world. ${ }^{46}$

Ketamine should be used cautiously in patients at increased seizure risk. The dealers sell the drug in liquid form. This substance is odorless and tasteless, making it easy to slip into drinks without being detected. The memory loss aspect of the drug is why individuals use it in the commission of sexual assaults. A victim can be drugged unknowingly, attacked and be completely unaware of the attack afterward. For this reason, it is one of the most commonly abused dissociative drugs. ${ }^{47}$

In humans, it can induce and maintain general anesthesia before, during, and after surgery. For medical purposes, ketamine is either injected into a muscle or given through an intravenous (IV) line. It is considered safe as an anesthetic, because it does not reduce blood pressure or lower the breathing rate. The fact that it does not need an electricity supply, oxygen, or highly trained staff which makes it a suitable option in less wealthy countries and in disaster zones. ${ }^{48}$

Telazol ${ }^{\circledR}$ has been used extensively in exotic large animal (large cats, pigs, and hoofstock) as a darting agent for immobilization. Telazol ${ }^{\circledR}$ comes as a powder and needs to be re-constituted with $5 \mathrm{ml}$ solution of sterile water or other liquid solution of choice (e.g., ketamine, xylazine). Following reconstitution with sterile water, each $\mathrm{ml}$ of solution contains $100 \mathrm{mg}$ of Telazol ${ }^{\circledR}$ (50 $\mathrm{mg}$ of tiletamine and $50 \mathrm{mg}$ of zolazepam) per $\mathrm{ml}^{49}$

Some of the use of common dissociative anaesthetics and its dose are described below in table 1:

\begin{tabular}{|c|c|c|}
\hline \multirow{2}{*}{ Species } & \multicolumn{2}{|c|}{ Dose $(\mathrm{Mg} / \mathrm{Kg})$ and respective rout of administration } \\
\hline & Ketamine & Tiletamine/Zolazepum \\
\hline Dog & $5-10 \mathrm{IV}$ & $\begin{array}{l}\text { I IV } \\
3-6 \mathrm{IM}\end{array}$ \\
\hline Cat & $\begin{array}{l}5-10 \text { IV } \\
5-15 \text { IM }\end{array}$ & $\begin{array}{l}3-61 M \\
4-71 M\end{array}$ \\
\hline Horse & $\begin{array}{c}2-2.2 \mathrm{IV} \\
\text { (after adequate } \\
\text { sedation) }\end{array}$ & $\begin{array}{c}\text { I-3 IV } \\
\text { (after adequate sedation with } \\
\text { appropriate sedatives) }\end{array}$ \\
\hline Cattle & $2-4 \mathrm{IV}$ & $2-4$ IV \\
\hline Pig & $10 \mathrm{IM}$ & $6 \mathrm{IM}$ \\
\hline
\end{tabular}

\section{ADVERSE EFFECTS}

High doses of the drug can lead to respiratory depression severe enough to cause death. Although it is invaluable drug it has many adverse effects. The most prominent disadvantage of their use is that, depending on dose, this class of drugs may cause CNS arousal in some species (e.g., horse) leading to animal excitement or frank convulsions. ${ }^{50}$ The others are summarized below in both animals and humans.

I. The increase in muscle tone produced by ketamine makes it unsuitable for operations where muscle relaxation is needed.

II. It is not indicated in conditions like hypertension, schizophrenia and raised intraocular pressure.

III. Though ketamine well maintains the airway, some form of airway compromise needing manipulation can occur.

IV. It produces dose dependent psychological manifestations like emergence reactions, dreams, hallucinations and long-term psychotomimetic effects.

V. Ketamine has the potential to cause addiction.

VI. Ulcerative cystitis, secondary renal damage and hepatic failure can occur with high doses of oral ketamine.

VII. Frequent ketamine abuse can cause long standing memory impairment.

VIII. Anesthetic concentrations of ketamine could exert antagonistic actions on both $\mu$ and $\mathrm{k}$ opioid receptors and hence high doses of ketamine may not be an appropriate addition to opioids.

IX. Epidural and spinal routes of administration of ketamine are generally not recommended due to unclear toxicity issues.

$\mathrm{X}$. High dose ketamine accentuates apoptosis in the newborn brain of animals. Release of neurotoxic mediators may cause neuronal apoptosis and consequent neuronal damage in humans. ${ }^{51}$

Others are both hypothermia and hyperthermia. Hypothermia is due to its effect on thermoregulatory centers, while hyperthermia is due to increased muscle activity or hyperactive behavioral change.

\section{COMPATIBLE DRUG COMBINATIONS OF DISSOCIATIVE ANAESTHETICS}

Ketamine is being used in various combinations in horses and cattle to "stun" the animal to allow brief noxious procedures such as castration or dehorning. Sometimes, drug combinations are marketed to provide ready access to clinical benefits of two drugs while attempting to minimize their individual disadvantages. The combination improves the reliability of the sedative properties of either drug used alone without adding extensively to further vital organ depression (e.g., cardiopulmonary depression). Similarly the pharmacological actions of tiletamine and zolazepam are complementary to each other with providing analgesia and immobilization from the former and providing muscle relaxation and tranquilization from later one. However, as a consequence of the fixed 
combination, a prolonged duration of effect may be an unwanted result. $^{52}$

Tiletamine/zolazepam powder (500 $\mathrm{mg}$ ) has been reconstituted with xylazine $(100 \mathrm{mg})$ and ketamine $(400 \mathrm{mg})$ to form a potent chemical restraint/anesthesia cocktail that can be administered intramuscularly. But care must be exercised when administering the drug combination since the overall volume is very small and accurate measurement is important. Additionally, careful patient monitoring to prevent profound hypothermia is required since prolonged recovery may result due to low metabolism. ${ }^{53}$

The total dose required to induce anesthesia will be affected by premedication, the patient's physical status, and route of administration. Clinicians should evaluate patients carefully to determine if the dosage needs to be altered. Depending on the dose administered chemical immobilization to general anesthesia.
Onset of action occurs within 10 min of intramuscular injection. Duration of anesthesia is dependent on the dose administered, but usually longer following intramuscular injection due to the higher overall dose. ${ }^{54}$

Reversal of the sedative/tranquilizer used in combination with the dissociative should not occur until the effects of the dissociative have waned. Early reversal of sedatives may lead to emergence delirium and a rough recovery. Intravenous administration of ketamine plus a benzodiazepine or tiletamine/zolazepam combinations results in anesthetic induction in approximately 45-90s. Anesthetic duration of a single induction dose of ketamine/diazepam or tiletamine/zolazepam combinations is approximately $20 \mathrm{~min}$. Recovery from IV dissociative administration is usually of good quality, especially if other drugs (e.g., $\alpha 2$-adrenergic receptor agonists) are co-administered or anesthesia prolonged with inhalants. ${ }^{55}$

\begin{tabular}{|c|c|c|c|c|}
\hline Agent & Dose mg/kg & Route & $\begin{array}{l}\text { Duration } \\
\text { (minute) }\end{array}$ & Effect \\
\hline $\begin{array}{l}\text { Ketamine } \\
\text { Alone }\end{array}$ & 10 & IV & $7-23$ & $\begin{array}{c}\text { Short duration, } \\
\text { anesthesia inadequate } \\
\text { for surgery }\end{array}$ \\
\hline $\begin{array}{l}\text { Acepromazine } \\
\text { Ketamine }\end{array}$ & $0.2-10$ & IV & $31-47$ & $\begin{array}{l}\text { Clinical anesthesia, } \\
\text { less muscle rigidity }\end{array}$ \\
\hline $\begin{array}{l}\text { Xylazine } \\
\text { Ketamine }\end{array}$ & $\begin{array}{l}0.55-1.1 \mathrm{IM} \\
2.2 \mathrm{IV} \\
\text { to effect }\end{array}$ & IV/IM & $28-36$ & $\begin{array}{l}\text { Surgical anesthesia, } \\
\text { muscle relaxation, } \\
\text { analgesia for } \\
\text { abdominal surgery }\end{array}$ \\
\hline $\begin{array}{l}\text { Atropine } \\
\text { Xylazine } \\
\text { Ketamine }\end{array}$ & $\begin{array}{l}0.04 \\
1.1 \\
11\end{array}$ & IV & $17-35$ & $\begin{array}{l}\text { Increased risk with } \\
\text { dogs with } \\
\text { cardiopulmonary } \\
\text { compromise }\end{array}$ \\
\hline $\begin{array}{l}\text { Metomidine } \\
\text { Ketamine }\end{array}$ & $\begin{array}{c}0.04 \\
5\end{array}$ & IM & $25-35$ & $\begin{array}{l}\text { Longer muscle } \\
\text { relaxation and } \\
\text { recovery than } \\
\text { xylazine/ketamine }\end{array}$ \\
\hline $\begin{array}{l}\text { Diazapam } \\
\text { Ketamine }\end{array}$ & $\begin{array}{c}0.28 \\
5.5\end{array}$ & IV & & $\begin{array}{l}\text { Suitable induction for } \\
\text { Sighthounds }\end{array}$ \\
\hline
\end{tabular}

\begin{tabular}{|c|c|c|c|c|}
\hline Agent & Dose mg/kg & Route & $\begin{array}{l}\text { Duration } \\
\text { (minute) }\end{array}$ & Effect \\
\hline $\begin{array}{l}\text { Telazol } \\
\text { Alone }\end{array}$ & $\begin{array}{c}6-40 \\
\text { (average 12.8) }\end{array}$ & IM & $40-70$ & Salivation, apneustic breathing \\
\hline $\begin{array}{l}\text { Acepromazine } \\
\text { Telazol }\end{array}$ & $\begin{array}{c}0.1 \\
3.4 \pm 1.09\end{array}$ & IM & $30-50$ & $\begin{array}{l}\text { Adequate anesthesia for } \\
\text { castration }\end{array}$ \\
\hline $\begin{array}{l}\text { Telazol } \\
\text { Ketamine } \\
\text { Xylazine }\end{array}$ & $\begin{array}{c}3.3 \\
2.64 \\
0.66\end{array}$ & IM & $34-52$ & $\begin{array}{l}\text { Smooth induction and } \\
\text { recovery, excellent muscle } \\
\text { relaxation, good analgesia }\end{array}$ \\
\hline \multicolumn{5}{|l|}{ Source: ${ }^{57}$} \\
\hline
\end{tabular}

\begin{tabular}{|c|c|c|c|c|}
\hline Agent & Dose $\mathrm{mg} / \mathrm{kg}$ & Route & $\begin{array}{l}\text { Duration } \\
\text { (minute) }\end{array}$ & Effect \\
\hline Xylazine Ketamine & $\begin{array}{l}1.1 \\
2.2\end{array}$ & IV & $12-35$ & Smooth induction and recovery, inadequate muscle relaxation \\
\hline Xylazine Butorphanol Ketamine & $\begin{array}{c}\text { I.I } \\
0.1-0.2 \\
2.2\end{array}$ & IV & $\begin{array}{l}\text { 18-36 depending } \\
\text { on breed }\end{array}$ & 18-56 depending on breed \\
\hline $\begin{array}{l}\text { Acepromazine Methadone } \\
\text { Ketamine }\end{array}$ & $\begin{array}{c}0.04 \\
0.04 \\
2.0-2.5\end{array}$ & IV & $3-18$ & Muscle tremors \\
\hline Guiafenesin Xylazine Ketamine & $\begin{array}{l}50 \\
0.5 \\
1.0\end{array}$ & IV & 120 & Low blood pressure and hypoventilation \\
\hline $\begin{array}{l}\text { Methotrimeprazine Midazolam } \\
\text { Guaifenesin Ketamine }\end{array}$ & $\begin{array}{l}0.5 \\
0.1 \\
100 \\
1.6\end{array}$ & IV & & Induction of anesthesia, smooth recovery \\
\hline $\begin{array}{l}\text { Detomidine Butorphanol } \\
\text { Ketamine }\end{array}$ & $\begin{array}{c}0.02 \\
0.04 \\
2.2\end{array}$ & IV & $18-67$ & Smooth induction Smoother recoveryMuscle relaxation \\
\hline
\end{tabular}




\section{COMMON AND POSSIBLE COMPATIBLE COMBINATION IN DIFFERENT ANIMAL SPECIES}

Even though can be used alone based on circumstances, ketamine and tiletamine can be used with various combinations of anaesthetics in veterinary clinical practice.

\section{CONCLUSIONS AND RECCOMMENDATIONS}

Dissociative anesthetic combinations are effective anesthetic induction regimens and can be used both to induce and maintain anesthesia in surgical procedures of mild to moderate intensity and short duration. Dissociative anesthesia resembles a cataleptic state in which the patient does not appear to be asleep, but does not respond to external stimuli. Ketamine and tiletemine are the common drug of this group. These drugs are mainly characterized by analgesia and superficial sleep with good somatic analgesia but poor visceral analgesia and muscle relaxation. They are non-competitive antagonists at the NMDA receptor and prevent glutamate, an excitatory neurotransmitter, from binding. Prevention of glutamate binding results in depression of the thalamocortical, limbic, and reticular activating systems.

They are extensively used in domestic animals either alone or in combination with other combatable drugs for different purpose in safe manner with few complications. Although some reviews and research findings are conducted regarding dissociative anaesthetics and its combination with other compatible drugs in veterinary clinical use, the information is highly scattered, not well compiled and presented for commercialization. So depending on the conclusion the following are recommended.

- Further review should be compiled and used for commercialization.

- Further research should be conducted on combination of dissociative with other combatable drugs.

\section{ACKNOWLEDGEMENTS}

Abebe Fromsa have played significant role starting from the preparation to the final submission and consequently to publication process.

\section{CONFLICTS OF INTEREST}

The authors declare that they have no conflicts of interest.

\section{REFERENCES}

1. Anthony A. Anesthesiology Department, University Medical Center Groningen, University of Groningen. The Netherlands. Web site: https://www.researchgate.net/profile/Anthony_Absalom. 2014.

2. Bell RF, Dahl JB, Moore RA, Kalso E. Perioperative ketamine for acute postoperative pain. Cocbrane Database Syst Rev. 2006; 25: CD004603. doi: 10.1002/14651858.CD004603.pub2
3. Yamashita K, Wijayathilaka TP, Kushiro T, et al. Anesthetic and Cardiopulmonary Effects of Total Intravenous Anesthesia Using a midazolam, ketamine and medetomidine drug combination in horses. J Vet Med Sci. 2007; 69: 7-13. doi: 10.1292/jvms.69.7

4. Hall LW, Clarke KW, Trim CM. Veterinary Anaesthesia (10th Edition). Philadelphia, US: Saunders Ltd. 2001.

5. Sinclair MD. A review of physiological effects of alpha 2-agonists related to the clinical use of medetomidine in small animal practice. Can Vet J. 2003; 44: 885-897.

6. Kilic N. Cardiopulmonary, biochemical and haematological changes after detomidine-midazolam-ketamine anaesthesia in calves. Bull Vet Inst Pulawy. 2008; 52: 453-456.

7. Afshar FS, BaniAdam A, Marashipour SP. Effect of xylazineketamine on arterial blood pressure, arterial blood $\mathrm{pH}$, blood gases, rectal temperature, heart and respiratory rates in goats. Bull Vet Inst Pulawy. 2005; 49: 481-484.

8. Tamminga CA, Tanimoto K, Kuo S, et al. PCP-induced alterations in cerebral glucose utilization in rat brain: Blockade by metaphit, a PCP receptor-acylating agent. Synapse. 1987; 1: 497504. doi:10.1002/syn. 890010514

9. Bonta IL. Schizophrenia, dissociative anaesthesia and near-death experience; three events meeting at the NMDA receptor. Med Hypotheses. 2004; 62: 23-28. doi: 10.1016/S0306-9877(03)00307-4

10. Lyon L. Intravenous anesthetic agents and dissociatives. Veterinary Health Sciences. 2014; 1-14.

11. Zurek AA, Bridgwater EM, Orser BA. Inhibition of alpha5 $\gamma$-aminobutyric acid type A receptors restores recognitoin memory after general anesthesia. Anesth Analg. 2012; 114: 845-855. doi: 10.1213/ANE.0b013e31824720da

12. Johnston LD, O’Malley P.M, Bachman JG. Table 2: Trends in annual and 30 day prevalence of use of various drugs for eight, tenth, and twelfth graders. Monitoring the Future. 2002.

13. Drug Enforcement Administration(DEA), Drug Intelligence Brief: Club Drugs, an Update Web site: http://www.dea.gov/ pubs/intel/01026/index.html. Accessed February 10, 2003.

14. TD Consultancy Web site: http://tonydagostino.co.uk/history-of-ketamine-other-dissociative-anaesthetics/. Accessed November 8, 2018.

15. Canbay O, Celebi N, Sahin A, et al. Ketamine gargle for attenuating postoperative sore throat. BrJ Anaesth. 2008; 100: 490-493. doi:10.1093/bja/aen023

16. Huge V, Lauchart M, Magerl W, et al. Effects of low-dose intranasal (S)-ketamine in patients with neuropathic pain. Eur J Pain. 2010; 14: 387-394. doi: 10.1016/j.ejpain.2009.08.002 
17. Mathews DC, Zarate CA. Current status of ketamine and related compounds for depression. J Clin Psychiatry. 2013; 74: 516-517. doi: 10.4088/JCP.13ac08382

18. Zhang C, Davies MF, Guo TZ, Maze M. The analgesic action of nitrous oxide is dependent on the release of norepinephrine in the dorsal horn of the spinal cord. Anesthesiology. 1999; 91: 14011407.

19. Hirota K, Lambert DG. Ketamine: New uses for an old drug?. Br J Anaesth. 2011; 107: 123-126. doi: 10.1093/bja/aer221

20. Eger EI II, Xing Y, Pearce R et al. Isoflurane antagonizes the capacity of flurothyl or 1, 2-dichlorohexafluorocyclobutane to impair fear conditioning to context and tone. Anesth Analg. 2003; 96: 1010-1018. doi: 10.1213/01.ANE.0000055360.30078.FF

21. Yamakura T, Harris R. Effects of gaseous anesthetics nitrous oxide and xenon on ligand-gated ion channels: Comparison with isoflurane and ethanol. Anesthesiology. 2000; 93: 1095-1101. doi: 10.1097/00000542-200010000-00034

22. Persson J. Wherefore ketamine? Curr Opin Anaesthesiol. 2010; 23: 455-460. doi: 10.1097/ACO.0b013e32833b49b3

23. Rau V, Iyer SV, Oh I, et al. Gamma-aminobutyric acid type A receptor alpha 4 subunit knowckout mice are resistant to the amnesic effect of isoflurane. Anesth Analg. 2009; 109: 1816-1822. doi: 10.1213/ANE.0b013e3181bf6ae6

24. Honey GD, Corlett PR, Absalom AR, et al. Individual differences in psychotic effects of ketamine are predicted by brain function measured under placebo. J Neurosci. 2008; 28: 6295-6303. doi: 10.1523/JNEUROSCI.0910-08.2008

25. Yoon SH. Concerns of the anesthesiologist: Anesthetic induction in severe sepsis or septic shock patients. Korean J Anesthesiol. 2012; 63: 3-10. doi: 10.4097/kjae.2012.63.1.3

26. Green SM. Modern anesthesiologists receive limited training with ketamine: Implications for emergency medicine. Acad Emerg Med. 2000; 7: 839-841. doi: 10.1111/j.1553-2712.2000.tb02284.x

27. Goel S, Agrawal A. Ketamine in status asthmaticus: A review. Indian. J Crit Care Med. 2013; 17: 154-161. doi: 10.4103/09725229.117048

28. Annetta MG, Iemma D, Garisto C, et al. Ketamine: New indications for an old drug. Curr Drug Targets. 2005; 6: 789-794. doi: 10.2174/138945005774574533

29. Alkire MT, Nathan SV. Does the amygdala mediate anestheticinduced amnesia? Basolateral amygdala lesions block sevofluraneinduced amnesia. Anesthesiology. 2005; 102: 754-760.

30. Khanna P, Arora NK, Sunder RA. Adjuvants for intravenous regional anaesthesia. J Anaesthesiol Clin Pharmacol. 2010; 26: $287-$ 291.
31. Zhang Y, Eger EI, Dutton RC, Sonner JM. Inhaled anesthetics have hyperalgesic effects at 0.1 minimum alveolar anesthetic concentration. Anesth Analg. 2000; 91: 462-466. doi: 10.1097/00000539200008000-00044

32. Flood P, Sonner JM, Gong D, Coates MM. Isoflurane hyperalgesia is modulated by nicotinic inhibition. Anesthesiology. 2002; 97 : 192-198.

33. Dwyer RC, Rampil IJ, Eger EI II, Bennett HL. The electroencephalogram does not predict depth of isoflurane anesthesia. Anesthesiology. 1994; 81: 403-409. doi: 10.1097/00000542-19940800000019

34. Neigh JL, Garman JK, Harp JR. The electroencephalographic pattern during anesthesia with Ethrane: Effects of depth of anesthesia, PaCO2 and nitrous oxide. Anesthesiology. 1971; 35: 482-487.

35. Joas TA, Stevens WC, Eger EI II. Electroencephalographic seizure activity in dogs during anaesthesia: Studies with Ethrane, fluroxene, halothane, chloroform, divinyl ether, diethyl ether, methoxyflurane, cyclopropane and forane. Br J Anaesth. 1971; 43: 739745. doi: 10.1093/bja/43.8.739

36. Todd MM, Drummond JC. A comparison of the cerebrovascular and metabolic effects of halothane and isoflurane in the cat. Anesthesiology. 1984; 60: 276-282. doi: 10.1097/00000542198404000-00002

37. Fukuda H, Hirabayashi Y, Shimizu R, et al. Sevoflurane is equivalent to isoflurane for attenuating bupivacaine-induced arrhythmias and seizures in rats. Anesth Analg. 1996; 83: 570-573. doi: 10.1097/00000539-199609000-00023

38. Murao K, Shingu I, Tsushima K, et al. The anticonvulsant effects of volatile anesthetics on lidocaine-induced seizures in cats. Anesth Analg. 2000; 90: 148-155. doi: 10.1097/00000539200001000-00032

39. Luna SP, Cassu RN, Castro GB, et al. Effects of four anaesthetic protocols on the neurological and cardiorespiratory variables of puppies born by Caesarean section. Vet Rec. 2004; 154: 387-389. doi: $10.1136 /$ vr.154.13.387

40. Stanski DR. Monitoring depth of anesthesia. In: Miller RD, ed. Anesthesia, 5th edn. Philadelphia: Churchill Livingstone, 2000; 10: 87-116.

41. Holmstrom A, Akeson J. Desflurane increses intracranial pressure more and sevoflurane less than isoflurane in pigs subjected to intracranial hypertension. J Neurosurg Anesthesiol. 2004; 16: 136-143. doi: 10.1097/00008506-200404000-00005

42. Fresno L, Andaluz A, Moll X, García F. The effects on maternal and fetal cardiovascular and acid-base variables after the administration of etomidate in the pregnant ewe. Vet J. 2008; 177 : 94-103. doi: 10.1016/j.tvj1.2007.03.023 
43. Psatha E, Alibhai HI, Jimenez-Lozano A, et al. Clinical efficacy and cardiorespiratory effects of alfaxalone, or diazepam/ fentanyl for induction of anaesthesia in dogs that are a poor anaesthetic risk. Vet Anaesth Analg. 2011; 38: 24-36. doi: 10.1111/j.14672995.2010.00577.x

44. Ko JC, Williams BL, Smith VL, et al. Comparison of Telazol, Telazol-ketamine, Telazol-xylazine, and Telazol-ketamine-xylazine as chemical restraint and anesthetic induction combination in swine. Lab Anim Sci. 1993; 43: 476-480.

45. Coetzee JF, R Gehring, J Tarus-Sang. Effect of sub-anesthetic xylazine and ketamine ('ketamine stun') administered to calves immediately prior to castration. Vet Anaesth Analg. 2010; 37: 566-578. doi: 10.1111/j.1467-2995.2010.00573.x

46. Blonk MI, Koder BG, van den Bemt PM, Huygen FJ. Use of oral ketamine in chronic pain management: a review. Eur J Pain. 2010; 14: 466-472. doi: 10.1016/j.ejpain.2009.09.005

47. Sinner B, Graf BM. Ketamine. Hand book Exp Pharmacol. 2008; 182: 313-333. doi: 10.1007/978-3-540-74806-9_15

48. Duman RS, Li N, Liu RJ, Duric V, Aghajanian G. Signaling pathways underlying the rapid antidepressant actions of ketamine. Neuropharmacology. 2012; 62: 35-41. doi: 10.1016/j.neuropharm.2011.08.044

49. Kolawole IK. Ketamine hydrochloride: A useful but frequently misused drug. Niger J Surg Res; 2001; 3:118-125. doi: 10.4314/njsr. v3i3.12232
50. Fox SM. Chronic Pain in Small Animal Medicine. Boca Raton, Florida: CRC Press. 2009.

51. Kurdi MS, Theerth KA, Deva RS. Ketamine: Current applications in anesthesia, pain, and critical care. Anesth Essays Res. 2014; 8: 283-290. doi: 10.4103/0259-1162.143110

52. Clarke KC, Trim CM, Hall LW. Veterinary Anaesthesia. Edinburgh (Scotland), New York: Saunders. 2014.

53. Karnataka Institute of Medical Sciences. Anesthesia: Essays and Researches. Hubli, Karnataka, India: 2014; 8(3). 267-418

54. Ambrisko TD, Johnson CB, Chambers P. Effect of alfaxalone infusion on the electroencephalogram of dogs anaesthetized with halothane. Vet Anaesth Analg. 2011; 38: 529-535. doi: 10.1111/j.1467-2995.2011.00650.x

55. Sams L, Braun C, Allman D, Hofmeister E. A comparison of the effects of propofol and etomidate on the induction of anesthesia and on cardiopulmonary parameters in dogs. Vet Anaesth. Analg. 2008; 35: 488-494. doi: 10.1111/j.1467-2995.2008.00417.x

56. Tranquilli WJ, Thurmon JC, Grimm KA. Lumb and Jones' Veterinary Anesthesia and Analgesia, 4th edn. Hoboken, New Jersey: Blackwell Publishing; Figure 12.1, p.304. 2007.

57. Tranquilli WJ, Thurmon JC, Grimm KA. Lumb and Jones' Veterinary Anesthesia and Analgesia, 4th edn. Hoboken, New Jersey: Blackwell Publishing; Figure 12.4, p.308. 2007. 